\title{
Ways to Cultivate Students' Innovative Thinking in the Teaching of Oil Painting in Colleges
}

\author{
Yenan Gao* \\ Xi'an Fanyi University, Xi'an 710000, Shaanxi Province, China \\ *Corresponding author: Yenan Gao, 925545290@qq.com
}

\begin{abstract}
With the rapid development of information technology, oil painting, as an important part of art culture, plays an important role in foreign exchanges and the promotion of multicultural development. College education bears the responsibility of providing a steady stream of high-quality talents for the development of social culture and art in addition to bringing new vitality for the dissemination and development of art and cultural theories. Giving full play to the role of oil painting teaching in colleges to cultivate oil painting talents has become one of the top priorities. Therefore, colleges and universities should continue to promote the development and reform of oil painting teaching as well as better improve the overall quality and oil painting skills among college students. In the new era, innovative thinking is an indispensable core quality in students' learning and life. In contemporary oil painting teaching in colleges and universities, it is very important to cultivate students' innovative thinking ability. This article begins by discussing the development of oil painting in China and the characteristics of students' innovative thinking, analyzes the importance of cultivating students' innovative thinking, as well as explores effective ways to cultivate their innovative thinking in regard to oil painting.
\end{abstract}

Keywords: Oil painting teaching in colleges and universities; Talent training; Innovative thinking; Effective ways

Publication date: October 2021; Online publication: October 29, 2021

\section{Introduction}

Oil painting is different from other disciplines, in which it emphasizes more on the imagination and creativity of students. Einstein once said, "Imagination is more important than knowledge because knowledge is limited. Imagination sums up everything in the world." An oil painting would show the painter's inner world and the theme that he or she wishes to express. In oil painting teaching, teachers should stimulate students' innovative thinking through heuristic teaching, broaden their thinking, and cultivate their creativity ${ }^{[1]}$. The Party and the State regard cultivating students' innovative thinking and practical skills as the focus of quality education, thus putting forward higher requirements for oil painting teaching in colleges and universities. Therefore, implementing the decisions of the Central Committee of the Communist Party of China (CPC) and taking measures to cultivate students' innovative thinking is the primary task of college teachers. The development of oil painting in China only has a history of nearly a hundred years. Regardless of the material, style, technique, connotation, spirit, etc., they are relatively mature. Therefore, it has become a top priority for college oil painting teaching to focus on cultivating students' innovative thinking in order to promote the development of oil painting in the world's history.

\section{Development status of oil painting teaching in China}

Oil paintings are imported products from China. At the end of Ming Dynasty and the beginning of Qing Dynasty, western oil painting began to appear in the upper class as a work of artistic exchange; however, it was not loved and pursued by the Chinese people. In regard to time, oil painting began at the end of Ming 
Dynasty. At that time, Italian missionaries, Luo Ming, Ma Dou, and others brought works, such as the statue of the Virgin Mary, to China. Thereafter, Chinese talents began to actively learn oil painting and regarded oil painting as an art. Since the end of the 19th century and the beginning of the 20th century, oil painting has only developed in China for a hundred years ${ }^{[2]}$.

At the beginning of the 20th century, a number of advanced intellectuals began to establish art colleges. That was when the teaching of oil painting took root in China. Chinese oil painting has begun a new development process, showing strong vitality. In the new era, oil painting has stepped into a more active phase. People are constantly updating their concepts and are actively pursuing different styles ${ }^{[3]}$. However, in the face of new methods and ideas, there are also problems. For example, some people advocate abandoning realism and sketching while pursuing abstraction and change in applying them to the teaching of oil painting. In fact, the development of art does not speak of replacing old art with new ones. This is not innovation, but rather a monopoly, which is not conducive to the innovation and development of art. Although oil painting has a short history in China, it has been recognized by the world. One of the factors restricting the development of oil painting in China is the lack of innovation in the creation process. This is a huge challenge faced by the teaching of the oil painting in China's colleges and universities. It is necessary to reform and cultivate the teaching methods and innovative thinking of oil painting in colleges and universities.

\section{Connotation and characteristics of college students' innovative thinking}

\subsection{Connotation of innovative thinking}

Innovative thinking is a way of thinking differently from the conventional thinking. It is not restricted by basic knowledge or traditional methods but seeks the essence of objective facts from a higher level, thus proposing comprehensive solutions to problems. At present, with the rapid development of cultural diversity, the development of oil painting in China is no longer a single and local one. There is a realization that the comprehensive development of oil painting with other art forms cannot inherit and develop in the usual way of thinking but requires a deeper and more comprehensive innovative thinking to support its development ${ }^{[4]}$.

\subsection{Characteristics of innovative thinking}

(1) Innovative thinking is flexible. The flexibility of innovative thinking is reflected in the ability to break from the traditional thinking paradigms and behavioral norms, analyze and think about problems from multiple angles, as well as propose solutions to problems that keep pace with the times.

(2) Innovative thinking is individualized. Under the traditional mode of thinking, the development of various industries is in accordance with certain laws and methods. Under the influence of individualized innovative thinking, students can give full play to their existing life experience and cultural knowledge, realize unique thinking and analysis of things, and eventually achieve the result of innovative thinking.

(3) Innovative thinking is comprehensive. The formation of innovative thinking is the thinking ability obtained by summarizing various innovative behavioral activities. Therefore, when people encounter problems, they can quickly associate problems and reason under the guidance of innovative thinking, and then grasp the key and difficult points of the matter to create new answers [5]. 


\section{Effective ways to cultivate students' innovative thinking in the teaching of oil painting in colleges}

\subsection{Cultivate students' innovative thinking ability and establish correct innovative ideas}

Innovation is not a simple subversion of tradition, nor is it a blind, iconic, or whimsical innovation. These are incorrect innovation concepts. Innovation is the inheritance of tradition, and subsequently, the organic changes made according to the characteristics of the times. Therefore, oil painting innovation first requires educators and students to establish correct innovative ideas, then to have a targeted content and direction of innovation, with firm understanding that oil painting cannot lose its essential characteristics. In this manner, no matter how innovative concepts stimulate students' innovative ability, the students would not lose their way in the creative process.

\subsection{Encourage students to participate in interdisciplinary learning}

Art is a product of multiculturalism. Oil painting cannot be done behind closed doors; it is necessary to learn to absorb the essence of other types of art paintings. The richer the creator's knowledge, the more innovative the work will be. For example, the brush dyeing method in Chinese painting is similar to the transparent cover dyeing method in oil painting; thus, the painter can express the technique used in Chinese painting in the form of oil painting. These works are undoubtedly innovative. Watercolor and gouache are closely related to oil painting. Many famous oil painters use watercolor painting methods for layout and composition. Students in the new era should have such a sense of innovation, constantly enrich their artistic knowledge, and develop their own comprehensive oil painting skills.

\subsection{Colleges and universities should aim at cultivating innovative talents}

First, the concept of oil painting teaching in colleges and universities should be innovated. In traditional oil painting teaching, the use of fixed teaching concepts has largely led to the solidification of students' artistic creative thinking. At present, with the innovation of college oil painting teaching concepts, a variety of artistic creation concepts and diversified educational teaching concepts are introduced into college oil painting teaching activities, providing new directions for the teaching so that students would not only be restricted in their creation based on a certain oil painting style but would have the opportunity to carry out theoretical studies and apply excellent traditional Chinese art creation theories to western oil paintings to form works with Chinese characteristics. In addition, college oil painting teaching can also adopt new educational concepts, emphasize on a student-centered teaching model during teaching activities, update the teaching philosophy of advancing with the times, and coordinate the pulse of the development of the times with oil painting education in colleges. For example, in the teaching of Chinese painting and oil painting appreciation, the concept of advancing with the times should be adopted, the artistic concept of Chinese painting should be applied to oil paintings, and the appreciation of oil painting creation should be analyzed through material innovation. It can be said that the use of this innovative teaching concept and oil painting artistic creation concept would be able to break the traditional oil painting appreciation and traditional creative thinking as well as encourage students to think and analyze problems with comprehensive innovative thinking, so as to realize the cultivation of students' innovative thinking.

Second, a new goal should be established for the cultivation of oil painting talents. As far as the current oil painting teaching practices in colleges and universities are concerned, the teaching system focuses on the cultivation of students' theoretical knowledge and professional skills in oil painting, but the cultivation of students' comprehensive qualities and innovative thinking are neglected. At present, it is necessary to change this talent training goal and build an innovative new talent training and teaching system. For example, the studio teaching mode can be adopted, the traditional grade teaching activities can be changed, the age limit of students should be broken, the gap between teachers and students should be reduced, and 
cooperation as well as exploration can be emphasized. The shaping of such a democratic and equal teaching environment would encourage students to deeply experience the humanistic spirit and emotional connotation in oil painting works. In this way, every student would be able to receive individualized teaching guidance, thus laying a good platform for cultivating students' innovative thinking.

\subsection{Innovate and improve the oil painting teaching curriculum system in colleges and universities}

First, the teaching content of oil painting in colleges and universities should be enriched to provide a basis for cultivating students' innovative thinking. At present, the teaching of oil painting in colleges and universities emphasizes more on teaching students basic theories and professional skills. The proportion of various cultural courses is small, and the teaching content accepted by students is relatively fixed. It is impossible to carry out comprehensive and creative exploration as well as application of the knowledge they have learned. Therefore, colleges and universities need to increase the proportion of humanities in the teaching of oil painting, adjust the structure of teaching content, improve the humanistic quality of students, and improve their creative thinking ability. At the same time, schools can also strengthen the appreciation and analysis of various oil paintings so that students can perceive various styles and emotions from those oil paintings, master basic concepts, such as spatial structure and physical structure of oil paintings, as well as complete their own paintings. The thinking of the overall pattern law improves the depth and intensity of students' thinking about art works. Through the appreciation and analysis of many high-quality works, students can then portray strong self-creation and self-expression skills through oil painting creation activities.

Second, with the help of traditional Chinese art forms, the creation of oil paintings has developed innovatively. Although oil painting originated from the west, after it officially became an educational discipline, it gradually realized a creative development with local elements. At present, in oil painting teaching activities, it is necessary to encourage students to organically combine oil paintings with excellent traditional Chinese culture and regional cultural content. For example, China has rich cultural elements of ethnic minorities; thus, teachers should encourage students to draw strength from these excellent cultural elements and integrate them into their own oil paintings, so as to continuously enrich the connotation of their oil paintings and provide a more artistic and humanistic sense in their works.

Third, the teaching evaluation system should be innovated and reformed. The teaching evaluation system is an important standard to measure the quality and effect of education and teaching. It is of great significance to the sustainable development of oil painting teaching. At present, it is necessary to re-plan the content of the teaching evaluation system, introduce the indicators of students' innovative ability, innovative thinking, and innovative practical activities into the teaching evaluation, as well as evaluate students' mastery of innovative thinking abilities from multiple angles and levels, so as to ensure that students are improving from the teaching of oil painting in colleges and universities. The evaluation system can further improve their innovative thinking ability ${ }^{[3]}$.

\subsection{Create an environment conducive to cultivating students' innovative thinking}

In oil painting teaching, in order to better cultivate and stimulate students' innovative thinking, it is essential to create a good environment and promote the development of innovative thinking. Preparing facilities are important to cultivate innovative thinking. A large range of books and materials are also prerequisites, among which the latest international art materials are important for students to connect with the world and cultivate a sense of innovation. Philosophy and art are also closely related. In the case of abundant art related books, there should be some fringe subjects, such as philosophy books, which would help students understand the relationship between art and philosophy, thus finding inspiration for innovation. In addition, 
audiovisual materials are also essential. Oil painting is a visual art with strong intuition. Therefore, oil painting slides with vivid annotations are also favorable conditions for cultivating students' innovative thinking. In addition, in oil painting teaching, the materials, creative styles, and creative skills used in oil painting can also be improved. Paintings with different materials, techniques, and styles would produce different visual impacts. Teachers can also encourage students to explore boldly and stimulate their innovative thinking.

\subsection{Encourage students to use imagination and associate to further develop innovative thinking}

Objective things are interrelated. In universities, teachers should guide students to learn to associate. Association is the psychological change from one thing to another in reality. Lenovo encourages people to constantly make new discoveries, connect the things in their minds, as well as turn them into new ideas and understandings. Communication is the re-creation of reality and the result of innovation. Connecting a small fragment with multiple fragments to form new things and create highly unified imagination and products is the prerequisite for cultivating students' innovative thinking and the human brain potential. The Graphic Creativity Course has effectively promoted the development of students' innovative thinking ${ }^{[2]}$. This is of great help to stimulate students' thinking and associations in regard to oil painting creation. In addition, their imagination and association of works have also changed, which greatly promotes the development of innovative thinking among oil painting students.

\section{Conclusion}

Innovative thinking is a new way of thinking that is different from traditional thinking. With the development of multiculturalism, social economy and culture have shown the characteristics of diversified development. Traditional thinking cannot keep up with the trend of diversified social, economic, and cultural development. Only innovative thinking can solve problems and open up new paths, which would promote the rapid development of all sectors of society in the new era. The development and reform of oil painting require artists to have innovative thinking in order to create oil paintings, then promote the creative development of oil paintings and the innovation as well as perfection of related works and theories. Therefore, in education, colleges and universities should focus on cultivating students' innovative thinking in regard to oil painting through the reform of the curriculum system, the improvement of the evaluation index system, the strengthening of their innovative spirit, and the integration of innovative thinking into the goal of talent training. The teaching of oil painting does not only develop students' painting skills, but also their innovative thinking and perspective in solving problems, so that students can promote the development of oil painting art in a diversified art culture.

\section{Disclosure statement}

The author declares that there is no conflict of interest.

\section{References}

[1] Wang F, 2013, Research on the Cultivation of College Students' Innovative Thinking in University Oil Painting Teaching. Art Education Research, (22): 106.

[2] Xu Z, 2016, How to Effectively Cultivate Students' Innovative Thinking in College Oil Painting Teaching. Contemporary Educational Practice and Teaching Research, (07): 111.

[3] Zhang Z, 2017, How to Effectively Cultivate Students' Innovative Thinking in College Oil Painting Teaching. Art Education Research, (20): 140. 
[4] Wang Y, 2017, Discussion on Innovative Ways to Improve the Self-Learning Ability of College Students. Small and Medium Enterprise Management and Technology, (1): 100-101.

[5] Liu X, Wang L, 2017, Research on the Cultivation of College Students' Innovative Thinking. Innovation and Entrepreneurship Education, (3): 24-26. 